\title{
Strategies for increasing contraceptive use in factories in Barbados
}

Charles Alleyne

Elrene Sealy

Pauline Russell-Brown

Follow this and additional works at: https://knowledgecommons.popcouncil.org/departments_sbsr-rh

Part of the Social and Behavioral Sciences Commons How does access to this work benefit you? Let us know!

\section{Recommended Citation}

Alleyne, Charles, Elrene Sealy, and Pauline Russell-Brown. 1990. "Strategies for increasing contraceptive use in factories in Barbados," INOPAL Project Final Technical Report. Barbados Family Planning Association (BFPA) and Population Council. 


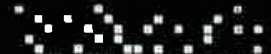
ing

INOPAL Project

Operations Research in Family Planning and Maternal-Child Health for Latin America and the Caribbean
Proyecto INOPAL.

Investigacion Operałiva en Planificación Familiar y Atención

Materno-Infantil para

América Latina y el Caribe
The

Population Council

BFPA/Barbados

Contract No. CI87.53A

"Strategies for Increasing contraceptive Use in Factories in Barbados"

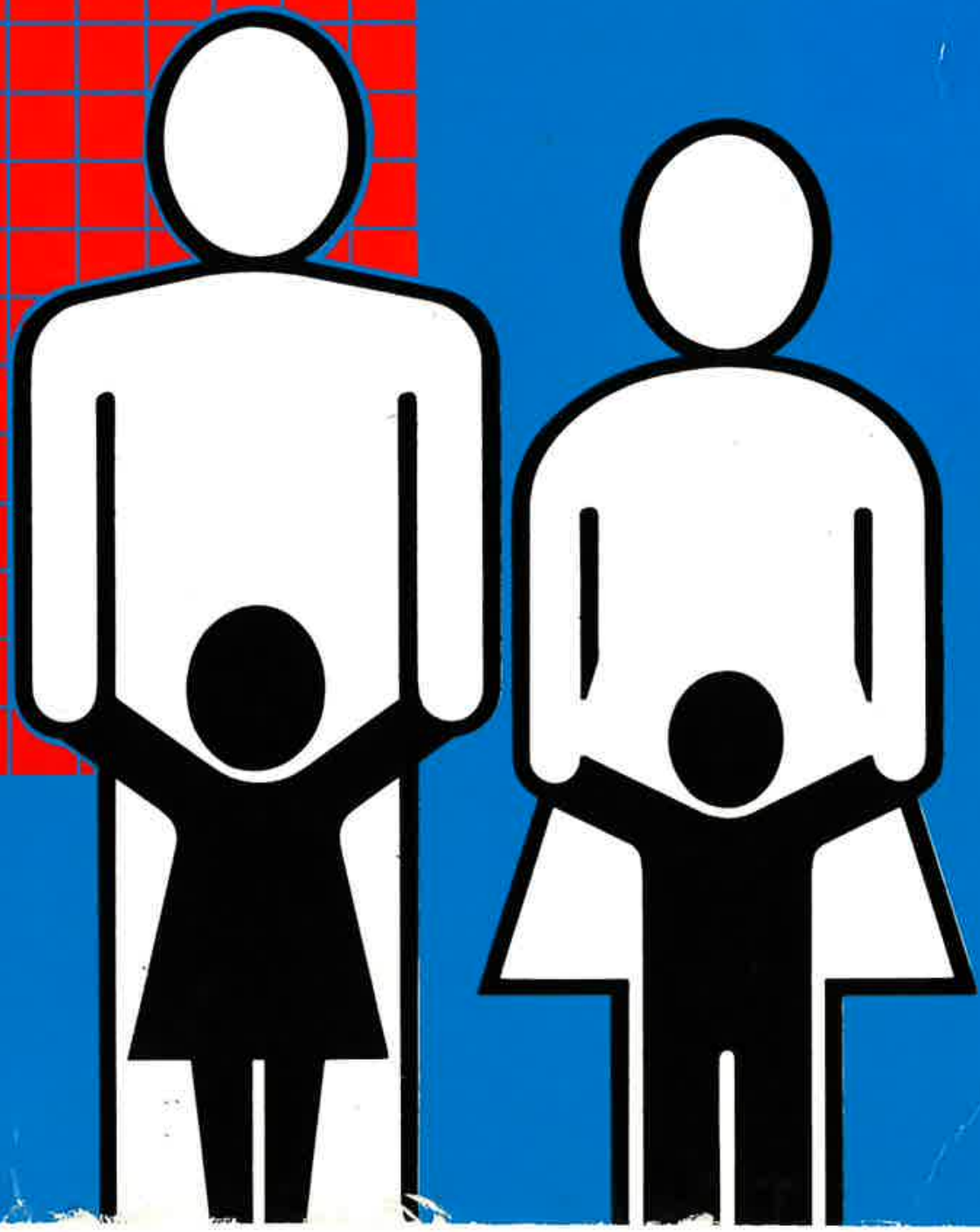


THE FOLLOWING IS THE BIBLIOGRAPHIC REFERENCE FOR THIS FINAL REPORT: Alleyne, C., Sealy, E. and Russell-Brown, P. 1990. "Strategies for Increasing Contraceptive use in Factories in Barbados." Final Technical Report, Barbados Family Planning Association (BFPA) and The Population Council. Barbados, West Indies. 
FINAL REPORT

\author{
"STRATEGIES FOR INCREASING \\ CONTRACEPTIVE USE IN FACTORIES \\ IN BARBADOS"
}

BFPA

(BARBADOS FAMILY PLANNING ASSOCIATION)

Contract No. CI87.53A

October 1, 1987 - September 13, 1989

The Population Council, an international, nonprofit organization established in 1952, undertakes social and health science programs and research relevant to developing countries and conducts biomedical research to develop and improve contraceptive technology. The council provides advice and technical assistance to governments, international agencies, and nongovernmental organizations, and it disseminates information on population issues through publications, conferences, seminars, and workshops:

This project is one of the 45 projects supported by the Population Council and funded by the U.S. Agency for International Development, office of Population, under contract No. AID/DPE3030-C-00-4074-00, Operations Research to Improve Family Planning and Maternal-Child Health Delivery Systems in Latin America and the Caribbean (INOPAL). 
Sirategies for Increasing Contraceptive Use in
Factories in Barbados

Contract No. CI87.53A

September 15, 1987 - September 13, 1989

\section{Charles Alleyne}

Elrene Sealy

Barbados Family Planning Association

Pauline Russell-Brown

The Population Counc1l 


\section{ACKNOWLEDGEMENT}

Several agencies and individuals were involved in the execution of this project and have given valuable assistance in making it a reality: Special thanks to the Management of the 22 factories which participated in the project. They allowed work schedules to be adjusted to accommodate the education and counseliling sessions.

To the distributors, for their interest and commitment to the project: Ms. Patricia Fairchild of John Snow Incorporated (JSI) for providing technical assistance with the cost-effectiveness analysis; the education and clinical staff of the BFPA for their contribution to the training exercises; the accounting staff of the BFPA for their assistance in completing the cost analysis. And finally, special thanks to the factory employees for assisting with the selection of the distributors and, most of all, for participating in the education and clinical service components of the project. 


\section{SUMMARY}

In spite of the relatively high levels of contraceptive usage and low total fertility rates, there remain areas of unmet need for family planning services in Barbados. Data from the 1980 contraceptive prevalence survey (CPS) for example, indicated that although 44.6 percent of women in union were using a contraceptive, contraceptive use was lowest among teenage women (27.6\%) and women 20-24 years of age $(33.68)$. What was more instructive was that several of the non-users of contraceptives in these age groups had no desire to have more children. In fact, more than one third of the women 15-24 years had no desire for additional children.

These data would suggest that although there is an island-wide network of family planning service outlets, family planning services were not readily accessible to young women. Location of service outlets vis-a-vis places of employment and the hours of opening (which tended to be the same as for other places of employment) have effected access, especially for individuals who are employed.

Notwithstanding the generally negative reviews given to factory-based family planning operations in the Caribbean, the BFPA felt that there were advantages to be gained, for the industrial sector in general, for the BFPA, and for factory employees, if factory-based services were implemented in Barbados. If a systematic attempt was made to demonstrate the relative effect of a well-organized factory-based programme on absenteeism and productivity, factory management could be convinced of the benefits of such programmes, which are often the first line of health care for many sexually-active individuals. They could then be encouraged to contribute to the implementation and maintenance of these programmes. Besides, the BFPA wanted to replicate the intervention in Barbados to determine the similarities and differences in experiences between the two caribbean settings - st. Iucia and Barbados.

A study designed to compare the relative effectiveness of two interventions: 1) on-going contraceptive distribution by a trained factory employee supported by monthly education visits by the BFPA (Group 2): and 2) monthly service and education visits by the BFPA (Group 1), was implemented in 31 factories. Factory management in each participating factory decided which of the two interventions would be introduced.

After 18 months of service activities, service and survey data indicated that the education/information programme component was stronger than the contraceptive delivery component. There were remarkable increases in the employees knowledge of contraceptive methods, especially in factories with employee distributors. However, only 22 new users were introduced to family planning and 108 active contraceptive users had purchased supplies from the 
work-based source. In terms of the effectiveness of the interventions in distributing contraceptives, $70 \%$ of the oral contraceptives and $60 \%$ of the condoms sold were sold in factories which had an employee distributor.

overall, employee distribution is relatively more cost effective than BFPA distribution. There is a lower cost per user by approximately $30 \%$ and a lower cost per couple-month of protection (CMP) 50\%. This is because it costs essentially the same to implement and operate the 2 interventions but the employee distributors are able to supply more contraceptives. Costs per educational session are also lower in Group 2 by about 25\%. Twice as many education sessions were conducted in Group 2 factories. The two exceptions to this conclusion are, 1) new users of contraceptives, which showed equal costs in both interventions, and 2) contraceptive users new to the programme, where employee distribution is $33 \%$ less expensive.

In many respects, the experience of the BFPA factory project is similar to that of the st. Lucia project conducted 4 years earlier. These two Caribbean experiences with factory-based delivery of family planning services lead us to reach the following conclusions:

* The commitment of factory managers to the provision of services is one of the most important factors in ensuring success of factory-based family planning service activities.

* Involving "workers in the selection of factorydistributors serves to foster positive attitudes to factorydistribution of family planning services and serves to strengthen and increase distributors! chances of acceptance by their peers.

* Programmes of this nature do not necessarily increase contraceptive prevalence but serve as an accessible and convenient source of supplies for active users.

* Peer distribution of contraceptive services in factories
is less costly than using the services of a trained nurse or
educator.

* The aggressive promotion of factory-based programmes must be an integral component of such programme. The spin-off of such promotion will be seen in the attitude of management and employees toward the programmes.

* Given the environment in which the manufacturing sector in the caribbean operates (relatively small labour force and unstable economies) it is not likely to expect that factory-based family planning services will become self sustaining. Parent organizations must be committed either to subsidizing these programmes or to persuading management to contribute financially to 
the programme.

The experience of the BFPA factory programme has demonstrated that given the relatively high levels of contraceptive use among factory employees, a critical mass of potential contraceptive acceptors is not available but there is a demonstrated desire among employees for more family planning and family life information. The primary thrust of factory-based family planning services in Barbados should therefore be to provide accessibie and convenient contraceptive supplies and services, with emphasis on education and counselling, rather than to necessarily increase contraceptive prevalence.

Recommendations of participants in a seminar organized for managers and workers in industry to discuss the factory-based family planning service programme. highlighted other needs. Employees recommended the provision of health insurance benefits for employees, accessible day care and childminder facilities; and family life and family planning education as measures of increasing employee productivity and performance.

The cost effectiveness analysis indicates that the BFPA will have to continue to provide financial inputs to sustain whichever service delivery strategy is adopted for the future. And especially if the needs of employees are to be addressed, management involvement and input must be strengthened. Given the similarities between the experience in St. Lucia and the experience of the BFPA, the BFPA would be well advised to establish closer links with the FPA in st. Lucia with a view to learning from the post-project experience of that FPA which has developed and implemented specific strategies for encouraging management investment in factory-based family planning service delivery. 


\section{TABLE OF CONTENTS}

$\begin{array}{ll}\text { SUMMARY } & \text { ii }\end{array}$

TABLE OF CONTENTS v v

I. PROBLEM DESCRIPTION 1

II. SOLUTION DEVELOPMENT

III. STUDY OBJECTIVES AND HYPOTHESIS

IV. METHODOLOGY 6

A. Research Design 6

B. Selection of Factories and Distributors 7

C. Assessment of Programme Effects 8

D. Cost Data 9

V. RESULTS II

A. Survey Finding 11

1. Intervention Group 1: Distribution by BFPA 11

a. Description of Respondents 11

b. Pregnancy and Chlldbearing 12

c. Contraceptive Knowledge and Practice 13

$\begin{array}{ll}\text { d. Knowledge and Attitude Towards } & 14 \\ \text { Work-based Services } & 14\end{array}$

2. Intervention Group 2: Employee Distribution 15

a. Description of Respondents 15

b. Pregnancy and Childbearing 16

c. Contraceptive Knowledge and Practice 16

d. Knowledge and Attitude Towards Work-based Services 18

$\begin{array}{ll}\text { B. Programe Outputs } & 18\end{array}$

c. Cost Analysis 19

VI. DISCUSSION AND CONCLUSIONS $\quad 22$

VII. DISSEMINATION 26

$\begin{array}{ll}\text { VIII.RECOMMENDATIONS FOR POLICY } & 27\end{array}$

$\begin{array}{lr}\text { REFERENCES } & 29\end{array}$

$\begin{array}{ll}\text { ATTACHMENTS } & 30\end{array}$ 
Barbados, the most eastern of the Caribbean Islands, is a small country of approximately 166 square miles in area. With a population of approximately 253,000 , Barbados is one of the most densely populated countries in the world. But with a total fertility rate (TFR) of 2.1 and a contraceptive prevalence rate of 61.98 of non-pregnant women in union (Jagdeo, 1989), the overall demographic profile of Barbados more closely resembles that of a developed country than a developing country.

Much of the credit for the decreasing fertility rates in all age groups and the high contraceptive prevalence rates, has been due to the efforts of the Barbados Family planning Association (BFPA), a private autonomous organization established in 1955. A member of the International Planned Parenthood Federation (IPPF), the BFPA receives financial support from the Government of Barbados.

Until 1983, the BFPA was the exclusive agency for the provision of clinic-based family planning services in Barbados. services were, until then, provided by BFPA staff at two sets of facilities: the BFPA's only clinic, operated at its headquarters, and in government health centres island-wide. These clinic-based services were supported by a community-based distribution (CBD) programme launched by the BFPA in 1975. The CBD programme utilized a wide range of commercial outlets island-wide and at present, contraceptive services are available from some 104 CBD outlets. The most recent data on utilization of contraceptive sources indicate that the commercial outlets are the outlets of choice among most contraceptive users: 47 percent of users of contraceptives reported obtaining supplies from pharmacies and shops. The BFPA clinic was the next most frequently used source of family planning services: some 20 percent of users surveyed obtained supplies from the BFPA clinic. (Jagdeo, 1989).

In spite of relatively high contraceptive usage and low total fertility rates, there remained, however, areas of unmet need for family planning services. For example, data from the 1980 contraceptive prevalence survey (CPS) indicated that although 44.6 percent of women in union were using a contraceptive, contraceptive use was lowest among teenage women (27.6\%). Further, the data suggested that needs for family planning services also existed for women in the 40-44 years and 20-24 years age groups where the prevalence of contraceptive use was $33.6 \%$ and $45.4 \%$ respectively. (Nair, 1982). What was more instructive was that several of the non-users of contraceptives in these age groups had no desire to have more children. In fact, more than one third of the women 1524 years had no desire for additional children. 
Undoubtedly these survey data highlighted a need for the provision of family planning services for young women: a need, which existed in spite of services being widely available in Barbados from a variety of sources. Sources, at that time, included commercial sources, the BFPA clinic, all government health centres, and private physicians and represented an island-wide network of service outlets. Why then should there be a need for services for young women? The matter of access to services is a possible explanation. It would appear that, in spite of wide-scale availability of family planning services, because of location of outlets vis-a-vis places of employment and opening hours (which tend to be the same as for other places of employment) the services were not easily accessible especially to individuals who are employed.

The argument for making family planning services more accessible to young women was further substantiated by anecdotal information available from factory managers. Managers of those factories in which there is a high female to male ratio, identify a problem of absenteeism among employees. They contend that, for the most part, absenteeism among female employees is related to childbearing and childrearing responsibilities and for them the situation is not acceptable. They cite the detrimental effect of absenteeism on productivity and the high costs (in dollars) to factory operations indirectly associated with absenteeism for maternity or child care responsibilities, employee turnover, and retraining or training replacement workers. The social costs to the employee and the family, of unplanned pregnancy, also make it important for family planning services to be more accessible to factory employees. 
In attempting to address these needs, the BFPA, in 1983, implemented a contraceptive distribution programme in factory-based settings. Factories which had a trained nurse who was willing to introduce family planning to factory employees, served as outlets for contraceptive supplies and services. BFPA staff made periodic visits to these factories to conduct education and counselling sessions and to resupply the plant distributors. A small number of other larger factories which did not have a nurse on staff were also included in the programme, but for those, the BFPA staff was responsible for providing supplies as well as for the education and counselling activities.

A number of important limitations, not the least of which were the increased use of human resources from the BFPA, transportation and a lack of commitment from factory managers to support the programme, resulted in the suspension of the programme. But low contraceptive use among young women remained a problem. And so services to industry continued to be perceived as vital, not only to the health of women but also to increased productivity in that sector, a sector which in March 1987 was reported to have a workforce of approximately 10,000 employees. It is estimated that in this workforce there are three times as many female workers as male workers and that as much as 85 percent of the female workers are below the age of 35 years.

One approach to the problem was to reorganize the family planning programme in industry in such a way as to provide more effective and efficient coverage of the factories. Instead of relying entirely on BFPA staff and the few health professionals employed in industry, the selection and training of workers as distributors was contemplated. Trained factory employees would serve as outlets for contraceptive supplies and could be supported by frequent counselling and education visits from the BFPA. To assess the relative success of the approach, it would be compared with service and education visits by one BFPA educator.

The decision to implement such a strategy was very courageous as well as controversial. The data had shown that factory-based family planning services in the Caribbean are costly. The cost per client measured in couple-year of protection or couple-moth of protection (CYP/CMP) is very high. In a very similar study conducted in St. Lucia between 1982 and 1985, the cost per CMP for factories which only had one monthly visit by a health professional was approximately us\$12, while for factories with an on-site employee distributor, cost per CMP was approximately Us\$ll (Landry, et al, 1986).

Notwithstanding the cost and the generally negative reviews given to factory-based family planning operations in the Caribbean, the BFPA felt that there were advantages to be gained, for the 
industrial sector in general, for the BFPA, and for factory employees, if the strategy was introduced. First, the BFPA wanted to replicate the intervention in Barbados to determine the similarities and differences in experiences between the two Caribbean settings - st. Lucia and Barbados.

Another priority of the BFPA was to provide data which would assist in encouraging non-participating factories to become involved in the factory-based family planning programme and so reduce the cost of providing the services. The support of employers was therefore important in this regard. It had been shown that employment-based family planning services are more likely to be well received and efficiently run if all groups involved are convinced that they are beneficial. (Rinehart, et al, 1987). The experience gained from the first efforts of the BFPA with work-based service delivery had also highlighted the importance of persuading management of the benefits of work-based family planning services. The introduction of a well organized and carefully monitored programme was essential in that regard. Further, the project would provide the data needed to demonstrate to the management of participating factories, the benefits of assuming a more active role in the delivery of family planning services for their employees.

The allocation of resources is always an important consideration within an agency like the BFPA. Consequently, if the BFPA was successful in encouraging increased management involvement in family planning/family life service delivery, more of the resources of the BFPA would ultimately become available to investigate other opportunities and address the unmet needs which exist in the distributive and hotel sectors of industry in Barbados.

Finally, from the clients' perspective, the introduction of work-based family planning services would be important as these services, oftentimes, are the first line of health care for many sexually active individuals. The project would, therefore, provide an opportunity to expand the community information and education efforts of the BFPA to include health topics which have a direct bearing on issues of family planning and sexual lifestyles. 


\section{STUDY OBJECTIVES AND HYPOTHESIS}

The goal of the industry operations research project was to increase contraceptive prevalence among factory workers in Barbados by improving access to services. The project designed, therefore, was to test approaches for reaching a larger number of working women (and men) in the high fertility age group in the industrial sector and to identify a more effective and less costly approach to providing family planning services in factories in Barbados.

The specific objectives of the project were:

1. To increase the awareness of factory employees about family planning;

2. To estimate the increase in knowledge and use of contraceptives produced by providing family planning services at the work place;

3. To determine the relative cost of providing family planning services using two different service models;

4. To demonstrate the relative benefits of the programme in reducing time lost due to pregnancy; and

5. To ascertain the effectiveness of an improved industrial project on the statistics of other service outlets.

The research was based on the hypothesis that providing contraceptives on site, together with regular education visits would increase contraceptive prevalence among factory employees. 
IV. METHODOLOGY

\section{A. Research Design}

The study was designed to compare the relative effectiveness of two interventions: 1) on-going contraceptive distribution by a trained factory employee supported by monthly education visits by the BFPA; and 2) monthly service and education visits by the BFPA. The long-term goal of the project was to enable the BFPA to improve its system of contraceptive service delivery to factory workers and provide a more efficient and cost-effective method of increasing contraceptive prevalence among factory workers.

In order to test the research hypothesis, a non-equivalent quasi-experimental research design was adopted. In this design, an experimental group of factories was compared with a similar but not equivalent group in which another intervention was introduced. Pre and post-intervention surveys were conducted. Ideally, an experimental design which included a control group would have allowed for a more accurate test of the effectiveness of the interventions. However, while this approach would have been ideal, it was not feasible under the circumstances. The number of factories which would have been eligible to participate in the project was too small and so it was decided to eliminate the control group.

Participating factories were assigned to one of two groups. Group 1 were factories which recelved monthly visits from a BFPA educator; and Group 2, factories serviced on an on-going basis by a trained factory employee and visited monthly by a BFPA educator. Employee distributors were expected to carry out the following tasks: sell contraceptives; answer basic questions about the contraceptives that they distributed; refer clients to the BFPA educator or other qualified individual; and maintain the data collection system. The BFPA educator provided individual counselling, group counselling, education and referral services, as well as contraceptive distribution in factories assigned to Group 1. The BFPA educator was also responsible for re-supplying the employee distributors.

Although the experience with factory-based family planning services in st. Lucia had shown that monthly service visits by a professional were very costly, it was agreed that the long-term benefits to be derived from those visits would far outweigh the cost. The monthly visit to the factories would be valuable in indicating to management that "something was happening" and so assists in sustaining their interest. The presence of the BFPA, especially in the early stages of the project, would also increase the chances that management would release workers to attend the education sessions. In the case of Group 2 factories, the visits by the BFPA would not only provide frequent opportunities for monitoring the performance of newly trained distributors but would 
serve as morale boosters for the distributors. The performance of the employee distributors would be enhanced by these frequent visits and the programme would then attain higher visibility.

\section{B. Selection of Factories and Distributors}

All registered factories in Barbajos which had an active workforce of at least 20 female employees and whose managers agreed to participate in the project, became eligible to receive one of the two interventions. Forty-nine of the 60 factories registered with the Barbados Industrial Development Corporation (IDC) met the first eligibility criteria. A total of 44 of the 49 eligible factories agreed initially to participate. Three factories refused to take part in the project, and 2 were omitted because of the transient nature of their work.

It was felt that, to a large extent, the success of the programme depended on the level of control and involvement of factory managers in all aspects of the implementation. Therefore, although the study design would have been strengthened by the random assignment of factories to treatment groups, this procedure was waived. Assignment of all factories to groups was based on the decision of the factory management. Each intervention model was explained to the manager and other senior management personnel in the participating factory. These individuals then decided which intervention should be introduced in their factory. Although assignment of factories to groups was not random, approximately equal numbers of eligible factories received each intervention. of the 31 factories which ultimately participated in the profect 14 agreed to be assigned to the Group 1 and the remaining 17 to Group 2. Prior to the implementation of service activities one factory had to be re-assigned. Table 1 indicates the type of factories participating in the programme and the respective group assignment.

For practical purposes, and as a means of maximizing the resources, the programme was conducted in two phases. Each phase included factories in both treatment groups. The same procedures were followed for each implementation phase. Altogether, 22 of the qualifying factories participated in the first implementation phase which lasted from November 1987 to June 1989. Twelve of the factories participating in the first phase were assigned to receive monthly visits from the BFPA (Group 1) and 10 to use employee distributors (Group 2). Nine factories: 3 in Group 1 and 6 in Group 2; participated in the second phase which was initiated in May 1988 and lasted until June 1989.

One worker, from each factory in Group 2, was selected by her peers, and approved by management, to be trained as a distributor. Each distributor participated in a 10-week basic training programme conducted on saturdays. The training sessions for distributors 
from factories in which the interventions would be introduced first (phase 1) extended from February to April 1988. The training programme for distributors in phase 2 factories was conducted between May 1988 and July 1988. The same training curriculum and resource persons were used for training both groups of distributors. Training was conducted primarily by resource persons drawn from the BFPA clinical and education staff.

In addition to the basic training, each distributor received refresher training organized by the BFPA. The refresher training curriculum was designed to update distributors' knowledge in appropriate areas of contraceptive technology, as well as to strengthen the areas of weakness identified during process assessment visits made to each work-site. The identified weaknesses were mainly in. the area of data collection and counselling.

Because of the extended period of basic training, the training programme was adjusted to enable the trainee-distributors to deliver contraceptives to their peers at the work-site after 5 weeks of basic training. Distribution of contraceptives in factories in Group 2 started in March 1988 when the first batch of trainee-distributors was considered competent to do so.

\section{Assessment of Programme Effects}

The factory-based family planning service activities were expected to produce at least two primary effects. Factory employees who were exposed to the interventions should demonstrate increased knowledge about contraceptive methods; and the level of contraceptive prevalence among factory workers should increase. These programme effects were measured in pre- and post-intervention sample surveys of factory workers. The surveys were also expected to provide data on employees' attitudes towards factory-based family planning services.

Baseline and follow-up surveys were conducted among workers in each factory participating in phase 1 of the project. The baseline survey, conducted in 22 factories was expected to provide core data on family planning use and awareness prior to the introduction of the intervention. The follow-up survey was designed to measure the effect of the intervention on contraceptive use, knowledge and attitudes. Only 21 factories participated in the follow-up survey.

The company's payroll served as the frame for selecting the sample of employees in each factory. To ensure a representative sample of male and female employees, a stratified sample design (with gender as the stratification factor) was used. Every third employee, male and female, appearing on the company payroll was selected and interviewed. Interviews were conducted at the worksite. The baseline survey was conducted between November 1987 and 
January 1988 by a team of trained interviewers. A second team of trained interviewers conducted the follow-up survey between June and July 1989.

Programme effect on contraceptive use was also assessed from service data collected in each factory. Distributors were trained to collect service information on an ongoing basis. These data included: 1) users new to program, that 1s, contraceptive users who had changed to the factory-based source; 2) continuing contraceptive users; and, 3) new contraceptive users. The volume of each type of contraceptive method sold each month and the number of counselling and education visits completed were also recorded. Service statistics collected routinely by factory distributors and the BFPA Educator, were used to compare the demand for counselling and education services and to compute the level of couple-month of protection (CMP) provided by each intervention model.

\section{Cost Data}

If factory-based services are to be continued, cost is one of the critical factors in determining the nature of the services to be provided. An analysis of the cost of implementing the interventions was therefore completed. specifically, cost information collected for the analysis were defined as:

a) Total cost of the programme: The costs of the program from inception through June 14, 1989 were used in the analysis. These costs were collected as part of the BFPA's accounting system. Total costs are important to know primarily to determine the impact of the intervention, expressed in terms of cost, on contraceptive usage in Barbados. The calculation of total costs is also important if replication of the intervention in other countries is being considered.

b) Development costs and on-going operational costs: These costs were analyzed separately. Separating development costs from on-going operating costs helps one to define the cost-effectiveness of the programme once the initial development has been completed and provides a more accurate assessment of the cost of continuing the service strategy.

c) Cost by major programme component: that is, the cost of providing each of the components: contraceptive distribution, counselling and education. Assessment of the cost by each programme component allows for more specific programmatic decisions.

d) Revenue: Revenue experience is important to determine the level of on-going subsidy required for the programme. Data on revenue generated by the programme were, therefore, also collected. The sale of contraceptives by employee-distributors and the BFPA 
educator was the only source of revenue generated by the project. These data were reported by the distributors, on a monthly basis, as part of their routine service data collection and reporting. 


\section{RESULTS}

The findings from the baseline and follow-up surveys and from the cost and effectiveness analyses are presented in this section of the report. The survey data provide the framework within which to assess the relative effectiveness of the interventions in increasing knowledge and use of contraceptives and in reducing pregnancy. These data also allow one to assess the attitude of workers towards employment-based family planning service delivery.

\section{A. Survey Findings}

Respondents in the baseline and follow-up surveys were selected from the set of 22 factories which participated in first phase of the programme, that is, those factories in which the interventions were introduced in January 1988. One of the factories (from Group 2) did not participate in the follow-up survey conducted approximately 18 months after introduction of the interventions: A total of 414 employees were interviewed in the baseline survey: 244 and 170 from Group 1 and Group 2 factories respectively, while 394 (252 from Group 1 and 142 from Group 2 factories) employees were interviewed in the follow-up survey.

Analysis of the survey data will be presented for each treatment group individually and will seek to highlight the similarities and differences between the two groups of factories.

\section{Intervention Group 1: Distribution by BFPA Educator}

\section{a. Description of Survey Respondents}

The sample of respondents interviewed in the baseline and follow-up surveys conducted in Group 1 factories were fairly similar in terms of age and sex. As indicated in Table 2, between $87 \%$ and $90 \%$ of the respondents wej:e female; and the mean age of the respondents in each survey was 27.8 and 27.9 years. One of the socio-demographic differences observed between the two sets of respondents was in union status. Approximately 2 out of 3 respondents in the baseline survey compared with $46.8 \%$ in the follow-up survey were in a visiting relationship while 9.48 of the baseline sample and 27.48 of the follow-up survey reported that they were single. The percentage of respondents reporting consensual union status was comparable for the two samples.

A greater percentage of graduates of secondary and technical institutions and individuals who had achieved higher that secondary level education were interviewed in the follow-up survey than in the baseline survey: $88 \%$ compared with $62 \%$. This difference appears to be related to composition of the workforce when the sample for follow-up survey was selected. As indicated in Table 3 , 
the follow-up survey sample included more data processing and supervisory personnel and fewer workers in undefined/unskilled employment categories. The sample of workers interviewed in Group 1 factories also included: machine operators (between $30 \%$ and 33\%): assemblers $(6-10 \%)$ and clerical processing workers $(3 \%-8 \%)$.

The survey data indicate that the work-force is relatively stable. Forty percent of the respondents were employed at the factory for more than 5 years; between $12 \%$ and $15 \%$ had been employed for between 4 and 5 years and some 15\%-21\% were in their present jobs for between one and 3 years. The remaining approximately $30 \%$ of respondents had been in employment for one year or less.

Absenteeism appears to be relatively high among employees of Group 1 factories. Some 558-64\% of employees reported being absent from work during the 3 months preceding the surveys. Personal illness, vacation and personal business were the most frequently reported reasons for absence from work. It is interesting to note that female employees were more often absent because of personal health reasons while male employees are absent for reasons of personal business.

Temporary layoffs contributed for between 8-13\% of the absence from work in Group 1 factories compared with only approximately $2 \%$ for Group 2 factories. This difference can be explained by the fact that there are more data processing factories represented in Group 1 . As indicated earlier, factories were not randomly assigned to treatment groups. Instead assignment but was based on preference of factory managers.

\section{b. Pregnancy and Childbearing}

More than half ( $53 \%$ and $52 \%$ ) of the employees interviewed from Group 1 factories had children. The majority of them (52.6r) had only one child. The mean number of children for respondents from Group 1 factories was 1.9 and 1.7 for the baseline and follow-up surveys respectively.

Ten of the respondents (4.18) were pregnant, or had a spouse who was pregnant, at the baseline survey compared with 12 (4.8\%) at the follow-up survey. An additional 16 respondents reported having had a child during the 12 months preceding the follow-up survey. Analysis of data on pregnancy planning, obtained only in the follow-up survey interview, indicate that only 4 of the 12 current pregnancies had been planned and that 10 of the pregnancies which had occurred in the intervening period had been planned.

Follow-up survey data indicate that 44 of the 130 respondents who had children wanted to have at least one more child. The total 
desired family size of the majority of the respondents who wanted children was two. Only approximately 258 of the respondents wanted to have 3 or more children. About one third (35.4\%) of the respondents had no desire to have any children at all. For the more than 608 who wanted children, 548 of them desired to have 2 children.

\section{c. Contraceptive Knowledge and Practice}

The intervention of the BFPA educator seems to have made a difference in employees knowledge of contraceptive methods. Knowledge about specific contraceptive methods measured in the baseline survey was relatively high but increased significantly, for most methods, by the second survey. As indicated in Table 4, the percentage of respondents in the baseline survey who knew about specific contraceptive methods, ranged from $92 \%$ for the pill to $31 \%$ for natural family planning (rhythm). After some 15 months, the percentage of respondents who were aware of specific contraceptive methods ranged from approximately 100 percent $(99.68)$ for the pill to $78 \%$ for natural family planning. The pill was the most well known method (92-100\%), followed by the condom (83-99\%) and spermicides (65-90\%). More than $90 \%$ of the respondents in the follow-up survey were aware of female sterilization.

Data presented in Table 5 indicate a very high level of ever use of contraceptives among employees in Group 1 factories. More than $90 \%$ of employees interviewed had used a contraceptive method at one time. However, only between $41 \%$ and $54 \%$ of all respondents were currently using. a contraceptive. Almost one third of the respondents who had stopped using a contraceptive were influenced by the absence of a sex partner. Other reasons reported for discontinuing contraceptive use were, desired pregnancy and the experience of side effects.

The mix of contraceptive methods used, as shown in Table 6 , varied between the two surveys. Approximately half (48.5\%) of ali Group 1 respondents in the baseline survey were using the pill; 20.5\%, the condom; and $9.8 \%$, female sterilization. A different method mix was reported by respondents in the follow-up survey. In that sample, fewer couples were using the pill and female sterilization: $43 \%$ and $4 \%$ respectively. However, a higher percentage were using the condom (26.9\%) and the IUD (11.5\%). The increased use of the condom may be a reflection of the union status of respondents in the follow-up survey. As indicated in Table 2 , more than $25 \%$ of the respondents were not in an established sexual union. It is also possible that the education component of the project, which included information on sexually transmitted diseases, including AIDS, had influenced sexually active individuals to use the condom.

Among the female population, there was a decrease in the percentage using a contraceptive at Time 1 compared with Time 2 . 
Contraceptive prevalence, measured as a percentage of all women was 54.3\% at the baseline survey compared to $40.8 \%$ at the follow-up survey. A similar decline is observed in prevalence levels reported for women in union: 59.28 compared to 55.68. This level of contraceptive prevalence compares favourably with the national statistics reported recently.

Most users of contraceptives obtained their supplies from a commercial outlet (see Table 6). The pharmacy or CBD outlet served as the source of supplies for between 398 and $57 \%$ of users. Note that a distinction between these two sources is not made here as several pharmacies in Barbados carry their own product lines while participating in the BFPA's CBD programme. The BFPA clinic is the source of supplies for between $11 \%$ and $16 \%$ of contraceptive users. The government polyclinic and private physicians represent a relatively insignificant source of supplies for employees in Group 1 factories. Only between $3 \%$ and $8 \%$ of contraceptive users purchase supplies from these sources.

One of the objectives of the programme was to ascertain the effectiveness of an improved factory-based family planning programme on the sales statistics of other family planning service outlets. In other words, would offering contraceptives at the work-place motivate contraceptive users to change their source of supplies. Data from the follow-up survey showed very low levels of source switching among users in Group 1 factories. Only 2 respondents reported changing their contraceptive source. One user switched from the BFPA clinic to the pharmacy and the other from the pharmacy to the factory-based programme.

\section{d. Knowledge and Attitude towards Work-based Services}

The attitude of employees towards the introduction of factorybased family planning services was assessed during the baseline survey. Employees were asked how they would respond to family planning services provided at the work-place either by BFPA staff or by a work colleague. The majority opinion (998) at that time was that the service offered by the BFPA distributor would be welcome because it was "necessary", that is, provision of the service would serve to improve access to needed family planning services. Table 7. Data collected during the follow-up survey indicate that employees in Group I factories were, at that time, still comfortable with the idea of factory-based family planning services provided by the BFPA educator; just over 958 of the respondents reported that they liked the idea.

Just over half of the respondents were aware that contraceptives were on sale at their factory and only $56 \%$ of those who know about the services were aware of the BFPA distributor. As indicated in Table 8 , some 438 of the respondents who knew about the factory-based contraceptive service outlet mentioned condom machines as the source. These machines are a recent introduction 
at selected locations in Barbados.

All factories assigned to Group 1 should have received one monthly visit from the BFPA educator. The visit must be approved by management but employees' attendance at the education sessions is not mandatory. Between April 1, 1988 and June 30, 1989, the educator had made a total of 55 education visits to Group 1 factories. However, as shown in Table 8, less than half (47.2\%) of the respondents in Group 1 factories were aware that the BFPA educator visited the factory to provide family planning services and only $50.8 \%$ of them knew that contraceptives were available from the BFPA educator.

Attendance at lectures among those who were aware of the service was relatively high - 66\%. However, in terms of the overall population, only $31 \%$ of the respondents attended family planning/family life lectures. All the respondents who attended the education sessions rated them useful.

\section{Intervention Group 2: Contraceptive Distribution by Peers}

\section{a. Description of Survey Respondents}

Iike the employees interviewed in Group 1 factories, the respondents from Group 2 factories were relatively young: mean age of 27.9 years and 29.6 years. As indicated in Table 2 , the samples selected in Group 2 compared with Group I factories, included more male employees: between $16 \%$ and $20 \%$ compared with between $10 \%$ and 13\%. Approximately one third of the respondents were in a consensual union; just over half (55\%-57\%) were in a visiting relationship and 158 or less were not in any established sexual union.

The mix of factories assigned to receive the Group 2 intervention is reflected in the respondents' job titles - Table 3. In that group of factories, which included mainly garment and electronic assembly operations, between 38\%-48\% of the employees interviewed were machine operators, approximately $30 \%$ were assemblers. As with the factories in Group 1, the sample selected for the follow-up survey included a greater percentage of supervisory personnel and fewer employees in unskilled categories.

The workforce in Group 2 factories seems to be more stable than that in Group 1 factories. Between $43 \%$ and $53 \%$ of the employees in Group 2 factories had been employed for more than 5 years and some $25 \%$ of the employees had been in their present job for between one and 5 years. The remaining 23\%-33\% had been in employment with the respective factory for only one year of less. Fewer temporary layoffs were reported by employees in Group 2 
factories. Only between $1 \%-2 \%$ of employees had been temporarily laid-off compared with between $8 \%$ and $15 \%$ in Group 1 factories.

b. Pregnancy and Childbearing

sixty-four percent of the respondents in the baseline survey had children while a somewhat higher percentage (70\%) of those interviewed in the follow-up survey were parents. The mean number of children for respondents in Group 2 factories was 1.89 and 1.94 .

The reported pregnancy rate among respondents in the baseline survey was lower in Group 2 than in Group 1 factories. Only 5 (2.9\%) respondents in Group 2 factories were pregnant, or had a spouse who was pregnant, when the baseline survey was conducted. six (4.2\%) pregnancies were reported at the follow-up survey. Three of the 6 pregnancies reported at Time 2 had been planned. Seventeen respondents had had children during the 12 months preceding the follow-up survey. Only 7 of these 27 pregnancies had been planned.

Respondents in the follow-up survey were asked to indicate their fertility desires. The data indicate that one third (33.6\%) of the respondents had no desire to have any children.

Approximately two thirds $(61.2 \%)$ of the respondents who wanted children desired a completed family size of 2 children. Only $10 \%$ wanted more than 3 children. These data, as are those for employees in Group 1 factories, are consistent with current total fertility rates for Barbados.

\section{c. Contraceptive Knowledge and Practice}

The pre-intervention level of awareness of contraceptive methods among respondents in Group 2 factories was lower than it was for respondents in Group 1 factories. Data on pre and post intervention knowledge of specific methods are presented in Table 4. The percentage of respondents who knew about specific methods ranged from $81 \%$ (pili) to $14 \%$ (natural family planning - rhythm). Less than $50 \%$ of the sample knew more than two methods, the pili and the condom.

Analysis of data from the follow-up survey leads one to conclude that the information and education inputs in Group 2 factories have been very successful. Information presented in Table 4 show remarkable changes in contraceptive knowledge between Time 1 and Time 2 for all methods. Knowledge of contraceptive methods measured in the follow-up survey ranged from 1008 for the pill to $75 \%$ for the natural method.

One of the factors contributing to increased awareness about contraceptive methods is the consistency with which sessions were conducted in Group 2 factories. The educator reports that there 
were fewer requests for the cancellation of education visits from management of Group 2 compared with Group 1 factories. Data reported elsewhere indicate that, ultimately, the BFPA educator completed approximately twice as many education visits to Group 2 as to Group 1 factories.

There are two possible explanations for the difference in the number of education visits conducted. The first is related to factory assignment and the second to the influence of the workerdistributor on programme operations. Group 1 is comprised a larger number of data processing operations. Production in these factories is influenced to a greater extent by the external market. Consequently, they report a higher incidence of temporary closures and inflexible production schedules. During peak production periods, managers are forced to cancel extra-curricular activities. As for the influence of employee distributors on the number of education visits; their presence provides the programme with greater visibility which seems to encourage more management and worker concern and interest in the programme. The result is fewer cancellations of education sessions.

While there were changes in knowledge of contraceptive methods between Time 1 and Time 2 in Group 2 factories, there was also a change in the level of contraceptive prevalence. Some 548 of all women in the baseline survey were using a contraceptive method compared to $46.5 \%$ of all women in the follow-up survey. Contraceptive use computed for women in union, however, showed an increase from $62.1 \%$ to $66.3 \%$.

57\%) (see mable 6). The condom and the IUD were the second and third most frequently used methods: less than 208 of the respondents used these methods.

Commercial outlets are the usual source of contraceptive supplies for most current users. Between $36 \%$ and $41 \%$ of the contraceptive users in Group 2 factories purchased their supplies from pharmacies or CBD outlets. Between $13 \%$ and $20 \%$ of current users obtained supplies from the BFPA clinic; 98 from government clinics: and $7 \%$ from private physicians. These data are similar to data obtained in the most recent contraceptive prevalence survey conducted in Barbados (Jagdeo, 1989).

Switching of source of supplies was one of the expected outcomes of the intervention. It was argued that easier access to services would motivate contraceptive users to change to the more convenient source - the factory-based outlet. Source switching, although not high, was greater for current contraceptive users in Group 2 factories than Group 1 factories. Survey data indicate that 8 current contraceptive users from Group 2 factories changed their source of supplies: 5 switched from the BFPA clinic and 3 from the pharmacy. Five of the 8 users who changed their source of 
supplies changed to purchasing supplies from the factory-based outlet.

\section{d. Knowledge and Attitude towards work-based Services}

Respondents from Group 2 factories have relatively positive attitudes towards factory-based family planning service delivery. The data presented in Table 7 indicate that the majority (85.9\%) of the employees interviewed in the baseline survey responded favourably to the idea of having contraceptives distributed at the work-place by their peers. The attitude toward peer distribution changed, however, once the intervention had been introduced. Only 618 of respondents in the follow-up survey favoured the idea of peer distribution of contraceptives.

As observed for Group 1 factories, Table 8, employees in Group 2 factories were not very aware of the factory-based services. Less than half $(47.9 \%)$ of the respondents from Group 2 factories knew that contraceptives were available from a source within the factory in which they worked and only 228 of those who knew about the service knew that contraceptives were available from a factory distributor. At the same time, more than $80 \%$ of the respondents were aware that the BFPA educator visited the factory to conduct education and counselling sessions and $81 \%$ of them had attended lectures. The influence of employee distributors on the scheduling and completion of education visits has already been highlighted. However, these data suggest that if the programme of employee distribution is to be effective, the service must be more actively promoted among the employee population.

\section{B. Programme Outputs}

Several outputs were tracked by the programme during the period January 1988 and June 1989. That information is presented in Table 9 and Table 10. Data in Table 9 are presented for the programme as a whole and for each of the two interventions individually.

\section{Contraceptive Users}

During the 18 months of service delivery, a total of 22 new contraceptive users (acceptors) were introduced to the programme: 11 in Group 1 and $i l$ in Group 2 factories. Additionally, as reported in Table 9, 108 active contraceptive users were introduced to the factory programme as a more convenient source of supplies. The service data indicate that the BFPA distributor was more successful than the trained factory employees in introducing active contraceptors to the factory programme: more than 608 of the users who were new to the programme, as a source of supplies, were introduced by the BFPA distributor. 


\section{Contraceptive distribution}

Three types of contraceptive methods were distributed within the factories: orals, condoms and spermicides. Employees wishing to use any other method were referred to the BFPA clinic. orals and condoms were the most popular methods distributed. A total of 601 cycles of oral contraceptives; 754 units of condoms; and 30 units of spermicides were distributed between April 1988 and June 1989. Approximately $70 \%$ of the orals, 908 of the spermicides and $60 \%$ of the condoms distributed by the programme were distributed in Group 2 factories, that is, factories with an employee distributor. Table 10. In terms of CMP, 666 CMP was provided to all factories, 200 CMP in Group 1 and 466 CMP in Group 2 factories. Figure 1 shows the relative performance of worker-distributors compared with the BFPA educator in terms contraceptive protection provided to factory employees.

\section{Education and counselling}

The protocol developed for the programme outlined at least one monthly visit to each participating factory. The visit, to be completed by the BFPA educator, was to be devoted to education and counselling of factory employees. The time available in each factory for counseliling and education was negotiated by the BFPA with the respective factory manager. Management agreed to allow at least 30 minutes, once per month; during the work day for the education and counselling but the arrangement was not always honored by management. During peak production periods, in particular, the time allocated for family planning education is not available. Factory closures for vacation also affected the education and counselling component of the project.

In spite of these constraints, a total of 141 education visits were made between April 1, 1988 and June 14, 1989. The visits were not equally distributed between Group 1 and Group 2 factories. As shown in Table 9, 55 visits were completed in Group 1 factories compared with 86 in Group 2 factories

\section{c. Cost Analysis}

The analysis focused on the cost and cost-effectiveness of the programme as a whole and for the two service models, individually. The effectiveness of the programme was assessed based on the following data: a) contraceptive users (acceptors); b) types and volume of contraceptives distributed and the resulting couplemonths of protection (CMP) provided; and c) educational activities. As with cost, these programme outputs were analyzed both for the programme as a whole and for each intervention model.

Since different decisions will require different information, programme costs will be presented in several different ways. Costs are presented both for the programme as a whole and for each of the 
two interventions being tested. All cost and revenue data are presented in Table 11, in Barbados dollars (equivalent to US\$0.5I). Several calculations have been done both to determine the costeffectiveness of the programme over the last 21 months and to provide BFPA with information for future programmatic activities. The major calculations for the cost analysis are presented in Table 12 .

Up to June 14, 1989, the programme had incurred costs of $\$ 91,233$ for 21 months of activity. The major costs were incurred in the area of personnel $(\$ 57,156)$, transportation $(\$ 20,140)$, training $(\$ 5,543)$ and office supplies/telephone $(\$ 6,346)$. A small amount of the total costs $(\$ 1,680)$ were related to BFPA's charges for administrative overhead.

In-kind contributions to the programme were minimal and include, space (BFPA gets their space in-kind from the Ministry of Health and in turn provides space to the industry project), utilities, totalling less than $\$ 1000$ per year, potentially some time of BFPA administrative staff not covered by the small contribution made by the project, (but all staff agreed $t_{i \text { ilat }}$ this was truly minimal) and contraceptives donated through IPPF. The value of these contraceptives has not been included in the analysis. Because in-kind contributions are minimal, they also were not considered a factor in the analysis.

An effort was made to separate development costs from the total costs of the programme. Development costs include all costs incurred before the programme became operational in March 1988 as well as all costs for training the employee distributors, with the exception of the "refresher" course costs which must be looked at as an on-going cost. On this basis, development costs were calculated at $\$ 18,466$ including $\$ 14,723$ pre-implementation salary, transportation and office costs and $\$ 3743$ training costs. Total costs without development costs are $\$ 72,767$.

An effort was also made to determine monthly costs required to operate the programme on an on-going basis as it is now structured. This information is essentlal for the BFPA to make decisions about the programme. In determining monthly costs, the major variable to be considered is the vehicle used by the BFPA educator to visit the industrial sites. The vehicle was initially charged to the programme at $\$ 1000$ per month to repay BFPA for purchasing the car. The present costs to the programme only include actual expenses for maintenance, petrol and oil, which average $\$ 325 /$ month. Based on discussions with the BFPA, it was determined that for the next two years, or so, the $\$ 325$ monthly cost would be realistic. This amount was therefore used in determining projected monthly operating costs. All other costs were determined by using the average cost for the last 4 months of programme operation. The projected monthly operating cost for the factory-based programme is $\$ 3700$ (US\$1869) exclusive of salary increases. 
Costs have been further broken down in two ways: 1) according to intervention model: Group 1 - serviced by the BFPA; and Group 2 - worker-distributors and monthly visits from the BFPA, and, 2) according to function (education/counselling versus contraceptive distribution). These break-downs have been done both for comparative cost analysis as well as to allow for future decision making. Costs were fairly evenly distributed among the two intervention models. This is because the level of effort to support the two interventions is, for the most part, equai. Group 2, with the employee distributors, however, has slightly higher costs due to time required for supporting the distributors; this works out at between 2-3 hours/month, and the recurring costs associated with required refresher "training sessions" - some $\$ 1500 / Y r$. These additional costs are offset somewhat by the higher revenue generated by Group 2 compared to Group 1 . It is, therefore, estimated that costs are apportioned among the two groups at $46 \%$ for Group 1 and $54 \%$ for Group 2 .

In apportioning the costs between the 2 programme functions (education and contraceptive distribution/counselling) the major factor considered was personnel time. It is estimated that $60 \%$ of the total costs were used for education while $40 \%$ were used for contraceptive distribution/counselling.

Revenue was generated through the sale of contraceptives at the rate of $\$ 3.00$ per cycle pills, $\$ 1.00$ per strip of 4 condoms and $\$ 2-4.00$ for spermicides. The employee distributors retain approximately $1 / 3$ of the price of each commodity as commission. The balance is returned to the BFPA. The average revenue generated, minus commissions, was $\$ 90.00$ per month over the last four months of programme activities. At the peak of the programme (April-December, 1988) the BFPA was realizing $\$ 116.00$ per month. This revenue is important but is not significant in offsetting project expenses as it represents less than 28 of the costs. 
The provision of work-based family planning services in Barbados is a priority for the BFPA. But based on the experience of the FPA in St Lucia in 1982 - 1985, and the BFPA's prior operations in industry in Barbados, several obstacles were anticipated in the development and introduction of a factory-based programme. The anticipated obstacles included workers' attitudes towards work-based services, cost, and the participation and contribution of factory management to the programme.

The data from this operations research project indicate that some of the anticipated obstacles can be overcome. For one, the attitude of factory employees to their peers providing family planning services is positive. And, although after more than one year of service delivery there is still some negative attitude towards the use of peers to distribute contraceptives, much of the resistance can be minimized through the careful selection and preparation of employee-distributors. The involvement of all employees in the selection of the distributor has also served to reduce the mistrust of the distributor which might otherwise have been present.

Another constraint to providing cost-effective factory-based family planning services, demonstrated in the st. Iucia experience and again in the current BFPA programe, is the cost of supervision. In both programmes supervision of the employeedistributors was conducted on a once-monthly basis. The cost of supervision could well be reduced if supervisory visits were reduced to say once each quarter. However, there are at least two reasons for not using that approach during the early stages of the programme. First, employee-distributors are persons who only have basic preparation and training in family planning. With relatively little preparation, they have to encourage employees to use the services, promote contraceptive use in general and provide facts about the contraceptives they sell. Close supervision and support from the parent organization in the early months of the programme is vital for their survival and for the survival of the programme. second, the frequent visits by programme sponsors provide management with a sense of security about the programme. This influence was reflected in the comparatively high number (twice as many of for Group 1) of education visits completed in factories with an employee-distributor.

While the interventions had a major effect on contraceptive knowledge, the effect on the prevalence of contraceptive use and on source switching was only minimal. One of the reasons may be that factory employees were not as well informed about the programme as one would have expected after more than one year of service activities. This finding suggests that an aggressive and well planned promotion effort must be launched in each factory. The more workers who know about the programme, the more likely it is 
that programme outputs will increase.

In terms of the cost effectiveness of the interventions, in general, employee distribution, is more cost effective than BFPA distribution. That is, there is a lower cost per user by approximately $30 \%$ and a lower cost per CMP (50\%) in factories with an employee distributor. This is because it costs essentially the same to implement and operate the 2 interventions but the employee distributors are able to supply more contraceptives. Costs per educational session are also lower in Group 2, by about 25\%, because more sessions were completed.

The two exceptions to this conclusion are, 1) new users of contraceptives, which showed equal costs in both interventions, and 2) contraceptive users new to the programme, where peer distribution is $33 \%$ less expensive. It would appear that the BFPA educator is important in introducing people to the service. These users can then be maintained by the employee distributors. overall, it must be recognized that this is not a programme which brings many new people into the system. Rather it is one which, if successful, offers convenience and improved access to those who are already contracepting.

Revenue generated from the sale of contraceptives were fairly minimal. Only $\$ 90$ per month or $2 \%$ of the $\$ 3700$ projected monthly operating budget was contributed through revenue. This finding has two important implications. First, the programme must continue to be subsidized at approximately BDS\$43,300 per year to maintain it in its current format. Second, it must be recognized that money from commissions on the sales of contraceptives is not sufficient to motivate and maintain the interest of distributors. The most productive distributors may earn no more than $\$ 10$ per month. . Other mechanisms must be used to keep distributors involved much like maintaining volunteers in other aspects of family planning.

Education is a major part of this programme, representing approximately $60 \%$ of staff efforts and costs. It is also the aspect which is best received by employers and employees. Qualitative information obtained during seminars and process reviews of the programme data indicate that there is need for continuing family planning information and education activities. Workers are anxious to learn more and as one factory distributor put it, "Bajan women are becoming more aware of health issues and are asking more questions". Another indication of the need for education and counselling is the high incidence of unplanned pregnancy. Approximately $50 \%$ of the most recent pregnancies among factory workers were not planned.

The education component was shown to be reasonably costeffective with on-going costs estimated to be approximately $\$ 185$ per session and $\$ 5.78$ per participant. If commitment to the industry programme remains, this component should be looked at 
carefully so that it continues to be seen positively. Ultimately, the education component can be a useful means of introducing new users and active contraceptors into the programme.

A finding which is not very encouraging is that the volume of services, particularly in the area of contraceptive supplies, declined during the latter months of the programme. Contraceptive services decreased $25 \%$ after it peaked in the period May-December 1988. After 15 months, one would have expected the programme to be growing. This decrease can be explained by at least two factors. First, fluctuations in the industrial sector due to factory closures and temporary lay-offs, and second, strict adherence to production deadines by factory managers. The latter reason does not allow distributors as much time to carry out the sales, education/promotion and initiation activities.

Implementation of this project has not been easy. One of the obstacles that still stand in the way is the reluctance among factory managers to allow the programme activities to continue, even after agreeing to have it implemented in the first place. As always, production is the bottom-line. Surely we must make the connection for managers, between the provision of health and family planning services and increased productivity.

In many respects, the experience of the BFPA factory project is similar to that of the st. Lucia project conducted 4 years earlier. These two Caribbean experiences with work-based delivery of family planning services lead us to reach the following conclusions:

* The commitment of factory managers to the provision of services is one of the most important factors in ensuring success of factory-based family planning service activities.

* Involving workers in the selection of factorydistributors serves to foster positive attitudes to factorydistribution of family planning services and serves to strengthen and increase distributors' chances of acceptance by their peers.

* Programmes of this nature do not necessarily increase contraceptive prevalence but serve as an accessible and convenient source of supplies for active users.

* Peer distribution of contraceptive services in factory is less costly than using the services of a trained nurse or educator.

* The aggressive promotion of factory-based programmes must be an integral component of such programme. The spin-off of such promotion will be seen in the attitude of management and employees toward the programmes. 
* Given the environment in which the manufacturing sectior in the Caribbean operates (relatively small labour force and unstable economies) it is not likely to expect that factory-based family planning services will become self sustaining. Parent organizations must be committed either to subsidizing these programmes or to persuading management to contribute financially to the programme. 


\section{DISSEMINATION}

Although factory-based contraceptive service delivery is not a new strategy for the BFPA, this project is the first effort to systematically measure and compare the cost and the effectiveness of two strategies of providing those services. Consequently, the results are of particular interest to the BFPA in its efforts to inform and encourage factory management of the need to support family planning efforts. Further, as one of the pioneer FPAs in the Caribbean, the BFPA is always seeking to share its experiences with other FPAs in the region as well as internationally. To achieve these objectives, a variety of dissemination efforts have been conducted.

In May 1989, the Industry project formed part of the discussion during a regional operations research conference held in Barbados. The preliminary results of the project, as well as program experiences, were shared with health and family planning administrators from the rest of the region.

The BFPA has made use of several opportunities to disseminate the results of the project to senior and middle management in the industrial sector and to the worker-distributors. A special reception for factory managers and distributors was organized midway into the project. The opportunity was used to make a brief slide presentation of the development and implementation of the industry project. Some preliminary findings on the programme outputs for the two strategies were also presented.

To further its dissemination efforts, the BFPA hosted a oneday seminar on "Working Together in Industry" in August 1989. Seminar participants included upper and middle management from participating factories, representatives of the Industrial Development Corporation (IDC), worker distributors and staff of the BFPA. Findings of the project were presented at the seminar.

Four workshop sessions followed the presentation of the findings. During these sessions, participants discussed topics related to the provision of health and family planning-related services at the work place. The recommendations were far-reaching as they included not only family planning services but other services required for improved productivity. The recommendations from the workshop sessions have been incorporated into this report.

The BFPA will continue to use all available avenues to inform the relevant constituents about the factory-based family planning activities. The latest issue of FAMILY, the BFPA magazine featured the factory programme. As with other projects which are part of the INOPAI programme, staff of the BFPA will be encouraged to assist in the preparation of papers for presentation at international conferences and submission to professional journals. 
over the years, the role of the BFPA in the delivery of family planning services in Barbados has undergone a number of changes. The indications are that, as part of a programme of integrated maternal and child health care, the Ministry of Health, will shortly assume more responsibility for the delivery of family planning services in government health centres. In anticipation of that event the BFPA is gearing up to focus its attention on exploring and addressing other areas of need in the community. The BFPA feels that there is still a great need for emphasis to be placed on services in the industrial sector where, employees, because of work schedules and the location of plant-sites relative to family planning service outlets, do not have easy access to family planning services.

The BFPA is anxious that this need be addressed in a systematic way. The Association wants to expand its industrial programme to include the smaller industrial plants and factories outside of the industrial estates. It also wants to modify the system of service delivery in such a way as to increase contraceptive prevalence and reduce absenteeism, due to unplanned childbearing and other reproductive health reasons, among women under 30 years of age. The demonstrated effect of the programme on these factors will be a means to encourage and increase management involvement in service delivery.

Given the relatively high levels of contraceptive use among factory employees, a critical mass of potential contraceptive acceptors is not available but there is a demonstrated desire among employees for more family planning and family life information. The primary thrust of factory-based family planning services in Barbados should therefore be to provide accessible and convenient contraceptive supplies and services, with emphasis on education and counselling, rather than to necessarily increase contraceptive prevalence.

Recommendations of participants in a seminar organized for managers and workers in industry to discuss the factory-based family planning service programme highlighted other needs. Employees recommended the provision of health insurance benefits for employees, accessible day care and childminder facilities; and family life and family planning education as measures of increasing employee productivity and performance.

The cost effectiveness analysis has provided information which will assist the BFPA to make a decision about whether and in what format to continue the factory-based programme. The indications are that the BFPA will have to continue to provide financial inputs to sustain whichever service delivery strategy is adopted. If the needs of employees are to be addressed, management involvement must be strengthened. Given the similarities between the experience in 
st. Lucia and the experience of the BFPA, the BFPA would be well advised to establish closer links with the FPA in St. Lucia with a view to learning from the post-project experience of that FPA which has developed and implemented specific strategies for encouraging management investment in factory-based family planning service delivery. 
Jagdeo, Tirbani P. 1989. Preliminary Findings of Contraceptive Prevalence Survey, Barbados.

Landry, Evelyn G., Raymond Louisy, and Audrey George. 1986. Contraceptive Distribution in Factories in St. Iucia. Final Report of project condurted by Tulane University under contract $A I D / D P E-0632-C-00-2007-00$

Nair, Neal Kar 1982. Fertility and Family Planning in Barbados. Findings from the Contraceptive Prevalence survey 1980-81. Barbados Family Planning Association and Westinghouse Health Systems :

Rinehart, Ward, Richard Blackburn, and Sidney Moore. 1987. Employment-Based Family Planning Programs. Population Reports Series J, Number 24

Rosenhouse, Gribble, De La Vega, Yanome and suarez, "Family Planning Service Delivery strategies in an Industrial setting," Final Report, INOPAL Project with Materno-Infantil $y$ de Planificación Familiar de Ciudad Juarez, Chihuahua (MIPFAC). The Population Council, May 26, 1988. 
Attachments 


\section{Table 1}

Distribution of Factories by Group and Implementation Phase

\begin{tabular}{|c|c|c|c|c|c|}
\hline & \multicolumn{2}{|c|}{ Group 1} & \multicolumn{2}{|c|}{ Group 2} & \multirow[t]{2}{*}{ TOTAI } \\
\hline & & $\operatorname{Im}$ & ation & Phase & \\
\hline Factory & $\underline{I}$ & $\underline{2}$ & 1 & $\underline{2}$ & \\
\hline Garment & 4 & 1 & 3 & 2 & 10 \\
\hline Electronic & 2 & - & 4 & 2 & 8 \\
\hline Data Processing & 4 & - & 1 & - & 5 \\
\hline Printing & 1 & 1 & 1 & - & 3 \\
\hline other Manufacturing & - & 1 & 1 & 2 & 4 \\
\hline Food Processing & 1 & - & - & - & 1 \\
\hline TOTAL & 12 & 3 & 10 & 6 & 31 \\
\hline
\end{tabular}


Table $\underline{2}$

Socio-Demographic Characteristics of study Populations

Group 1

Before After

244

9.0

27.0

24.2

25.0

10.7

4.1

27.8

6.6

10.2

89.8

\section{Education \\ None/No information Primary \\ Secondary/Technical Beyond Secondary other}
Female
Union Status
Married/C/Law
Visiting
single
No information
$20-24$
$30-34$
$35-39$

$\begin{array}{rr}29.1 & 25.8 \\ 60.7 & 46.8 \\ 9.4 & 27.4 \\ 0.8 & -\end{array}$

28.8

56.5

14.7

54.9

11.3

0.7
Group 2

Before After

142

$\begin{array}{rc}0.8 & - \\ 18.0 & 12.3 \\ 67.6 & 84.9 \\ 7.0 & 2.8 \\ 6.6 & -\end{array}$

0.6

27.0

71.2

1.2

12.7

86.6

0.7 


\section{Table 3}

Job Titles for Respondents in Sample Surveys

\begin{tabular}{|c|c|c|c|c|}
\hline & \multicolumn{2}{|c|}{ Group 1} & \multicolumn{2}{|c|}{ Group 2} \\
\hline & Before & After & Before & After \\
\hline Sample size (n) & 244 & 252 & 170 & 142 \\
\hline Machine Operator & 32.8 & 29.9 & 38.8 & 48.3 \\
\hline $\begin{array}{l}\text { Data Processing } \\
\text { Operator }\end{array}$ & 27.9 & 46.1 & 1.8 & 0.0 \\
\hline Assembler & 6.1 & 9.8 & 28.2 & 30.3 \\
\hline clerical worker & 5.7 & 3.4 & 5.3 & 5.6 \\
\hline supervisor & 4.5 & 6.9 & 2.3 & 10.1 \\
\hline $\begin{array}{l}\text { Technician } \\
\text { (not specified) }\end{array}$ & 2.5 & 2.5 & 1.8 & 4.5 \\
\hline other & 20.5 & 1.5 & 21.8 & 1.1 \\
\hline
\end{tabular}




\section{Table 4}

Pre and Post-intervention Knowledge of Contraceptive Methods

\begin{tabular}{|c|c|c|c|c|}
\hline & \multicolumn{2}{|c|}{ Group 1} & \multicolumn{2}{|c|}{ Group 2} \\
\hline & Before & After & Before & After \\
\hline Sample Size (n) & 244 & 252 & 170 & 142 \\
\hline Pill & 92.2 & 99.6 & 80.8 & 100.0 \\
\hline Condom & 82.8 & 98.8 & 63.4 & 99.3 \\
\hline Spermicides & 65.2 & 90.1 & 36.6 & 93.7 \\
\hline IUD & 51.6 & 84.1 & 33.7 & 91.5 \\
\hline withdrawal & 47.1 & 87.7 & 26.2 & 92.3 \\
\hline Injection & 45.5 & 80.9 & 32.0 & 85.9 \\
\hline Diaphragm & 40.6 & 76.2 & 17.4 & 81.7 \\
\hline Female sterilization & 41.8 & 90.1 & 22.1 & 98.6 \\
\hline Vasectomy & 32.4 & 82.5 & 16.3 & 78.9 \\
\hline Rhythm & 31.1 & 77.9 & 14.0 & 74.6 \\
\hline
\end{tabular}




\section{Table 5}

Percentage Ever and Current Contraceptive Use Among Factory Employees

\begin{tabular}{ccccc} 
& Group 1 & & \multicolumn{2}{c}{ Group 2} \\
Contraceptive Use & Before & After & Before & After \\
\hline Sample size (n) & 244 & 252 & 170 & 142 \\
Ever use & 92.2 & 96.3 & 95.8 & 94.7 \\
& & & & \\
\cline { 2 - 5 } & & & & \\
Current use & & & & \\
(all respondents) & 54.1 & 41.3 & 47.6 & 46.5 \\
(all women) & 54.3 & 40.8 & 53.8 & 66.3 \\
(women in union) & 59.2 & 55.6 & 62.1 &
\end{tabular}




\section{Table 6}

Contraceptive Method and Source of supplies for Current Contraceptive Users

Group $1 \quad$ Group 2

Before After Before After

$\begin{array}{llll}244 & 252 & 170 & 142\end{array}$

Sample size (n)

$(n=132) \quad(n=104)$

$(n=81) \quad(n=68)$

Current method

48.5

43.3

49.4

57.3

Condom

20.5

26.9

19.8

16.2

Female sterilization

9.8

3.8

3.7

7.3

IUD

8.3

11.5

11.1

10.3

Injection

$4 \cdot 5$

1.0

2.5

4.5

6.7

7.4

1.5

Diaphragm

-

-

1.5

Withdrawal

\begin{tabular}{l}
-4.8 \\
\hline
\end{tabular}

3.7

2.9

Rhythm

3.8

1.0

2.5

1.0

\begin{tabular}{l}
$-\quad 3.0$ \\
\hline
\end{tabular}

Source of supplies

Pharmacy/CBD

BFPA Clinic

Polyclinic

Private MD
39.0

16.3

3.0

7.8
56.7

10.6

4.8

4.8
35.8

41.2

19.7

13.2

8.6

8.8

7.4

7.3 
Table 7

Employees' Attitude towards Work-Based Family Planning Services

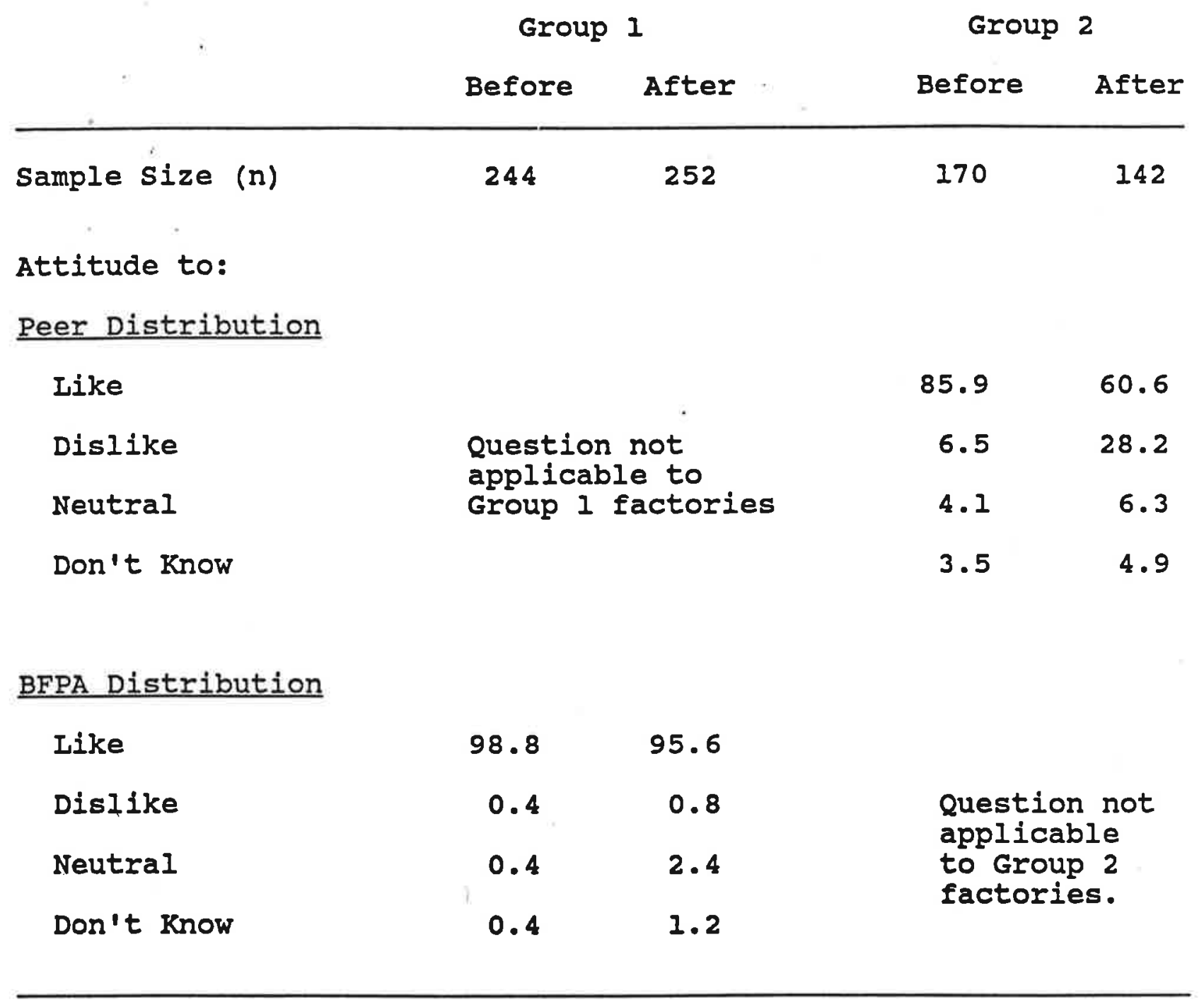


Knowledge and Use of Factory-based

Family Planning Services

Group 1

Group 2

$(n=252)$

$(n=142)$

\section{Contraceptives on}

sale at workplace

Yes

50.8

47.9

No

34.5

19.7

Don't know

14.7

$32 \cdot 4$

Source of supplies *

$(n=128)$

$(n=68)$

BFPA educator

55.5

77.9

Peer distributor

$-$

22.1

Condom machine

43.0

Don't know

1.6

Educator visits factory

$(n=252)$

$(n=142)$

Yes

47.2

83.8

No

35.3

8.5

Don't know

17.5

7.7

Attend lectures in factory **

$(n=119)$

$(n=119)$

Yes

66.4

80.7

No

31.9

18.5

No information

1.7

0.8

* Percentages are based on respondents who know about factory-based contraceptive service programme

** Percentages based on respondents who know about BFPA education 


\section{Table 9}

Program Outputs

March 1988 - June 1989

outputs

CMP

New Contraceptors

New to Program

old/Continuing users

Total Users

$\begin{array}{lr}22 \\ & 108 \\ \text { users } & 423\end{array}$

553

Total

665

22

23

620

141

32.5

12

\section{Group}

1

200

2

465

11

11

64

135

288

210

343

384

235

55

86

Avg. \# Participants

Avg. Educ. Sessions/Month

(Iast 4 months)

$32 \quad 33$

4.25

7.75 
Table 10

Volume of Contraceptives Distributed to Each Group

(Trimester 1988,89)

Group 1

\begin{tabular}{lrrrrrrr}
\hline Method & 1st & $\begin{array}{c}\text { 2nd } \\
1988\end{array}$ & 3rd & $\begin{array}{c}\text { Trimester } \\
\text { 4th }\end{array}$ & $\begin{array}{r}\text { 1st } \\
1989\end{array}$ & 2nd & TOTAL \\
\hline Orals & 27 & 46 & 39 & 33 & 21 & 17 & 183 \\
$\begin{array}{l}\text { Condoms } \\
\text { Spermicides }\end{array}$ & 24 & 104 & 44 & 42 & 40 & 48 & 302 \\
& - & 2 & - & 2 & 1 & - & 5 \\
\hline
\end{tabular}

Group 2

\begin{tabular}{|c|c|c|c|c|c|c|c|}
\hline \multirow[b]{2}{*}{ Method } & \multirow[b]{2}{*}{ lst } & \multicolumn{5}{|c|}{ Trimester } & \multirow[b]{2}{*}{ TOTAI } \\
\hline & & $\begin{array}{r}2 \text { nd } \\
1988\end{array}$ & $3 \mathrm{rd}$ & 4 th & $\begin{array}{l}\text { Ist } \\
1989\end{array}$ & 2nd & \\
\hline & & & $\cdot$ & & & & \\
\hline Orals & $\mathrm{NA}$ & 76 & 80 & 110 & 74 & 78 & 418 \\
\hline Condoms & NA & 142 & 120 & 28 & 126 & 36 & 452 \\
\hline Spermicide & $\mathrm{NA}$ & 2 & 1 & 1 & 14 & 9 & 27 \\
\hline
\end{tabular}

NA - Intervention not introduced, distributors in training

Note: The following units are used to report volume of contraceptives distributed: orals (cycles) condom (single piece) spermicides (tube) 


\section{Table 11}

Cost and Revenue Data

September 1987 - June 1989

\section{Costs}

Total Costs

$\$ 91,233$

Total Costs minus Development

$\$ 72,767$

Current Monthly Operating costs

$\$ 3,700$

Costs by Model

of Total

of Total Development

of Monthly Operations

\section{Group 1 \\ $46 \%$}

$\$ 41,967$

$\$ 33,472$

$\$ 1,702$
Group 2

$54 \%$

$\$ 49,266$

$\$ 39,295$

$\$ 1,998$

Costs of Education vs.

Distribution/Counselling services

608

$\$ 54,740$

of Total

of Monthly Operations
$40 \%$

$\$ 36,493$

$\$ 1,480$

Total Project Costs minus Education Costs

$\begin{array}{ll}\text { Overall Program } & \$ 36,493 \\ \text { Treatment 1 } & \$ 16,786 \\ \text { Treatment } 2 & \$ 19,706\end{array}$

\section{Revenue}

Current Avg. (last 4 mos.)

Avg. Apr. 88 - Dec. 88

Projected

$\$ 90.00-(86 \%$ Treatment 2)

$\$ 116.00$

$\$ 1200 \mathrm{yr}$. (85\% Treatment 2) 


\section{Table 12 \\ Cost-Effectiveness Ratios}

$\begin{array}{lcrr}\text { Development Cost per Industry }=\$ 18466 & 23=\$ 803 & \\ \text { Cost/CMP } & \text { Overall Program } & \text { Group I } & \text { Group II } \\ \text { Total } & \$ 137 & \$ 210 & \$ 106 \\ \text { Total-dev } & 109 & 167 & 84 \\ \text { Total-educ. } & 55 & 84 & 42\end{array}$

Cost/New Contraceptor

Total

Total-dev

Cost/New to Program

Total

Total-dev

$\$ 845$

674

Cost/old/Continuing
$\$ 215$

172

Total-dev

Total

Cost/Total Contraceptive Visits

\section{Total}

Total-dev

$\$ 165$

132

Total-educ

Cost/Total Visits Inc. Counsel

\section{Total}

Total-dev

Total-educ

Projected Costs/Visit

(based on $\$ 3,700$ Monthly Costs)

50 Contraceptive visit

56 Total Visit

\section{$\$ 147$}

117

59
$\$ 310$

248

$\$ 171$

136
Equal among the two

Total Without Education costs
$\$ 144$

114

$\begin{array}{rr}159 & 114 \\ 80 & 57\end{array}$

$\$ 200$

57 
Table 12 (Cont'd)

Cost-effectiveness Ratios

Educational Services

\section{Cost/Session}

Total

Total-dev
Total

$\$ 647$

516

Projected Cost/Session

Based on 12 sessions $4.25(1) \$ 185$

$7.75(2)$

Projected costs

per participant
I

II

$\$ 763$

608

$\$ 573$

457

$\$ 240$

$\$ 155$

$\$ 5.78$

7.50

4.69 


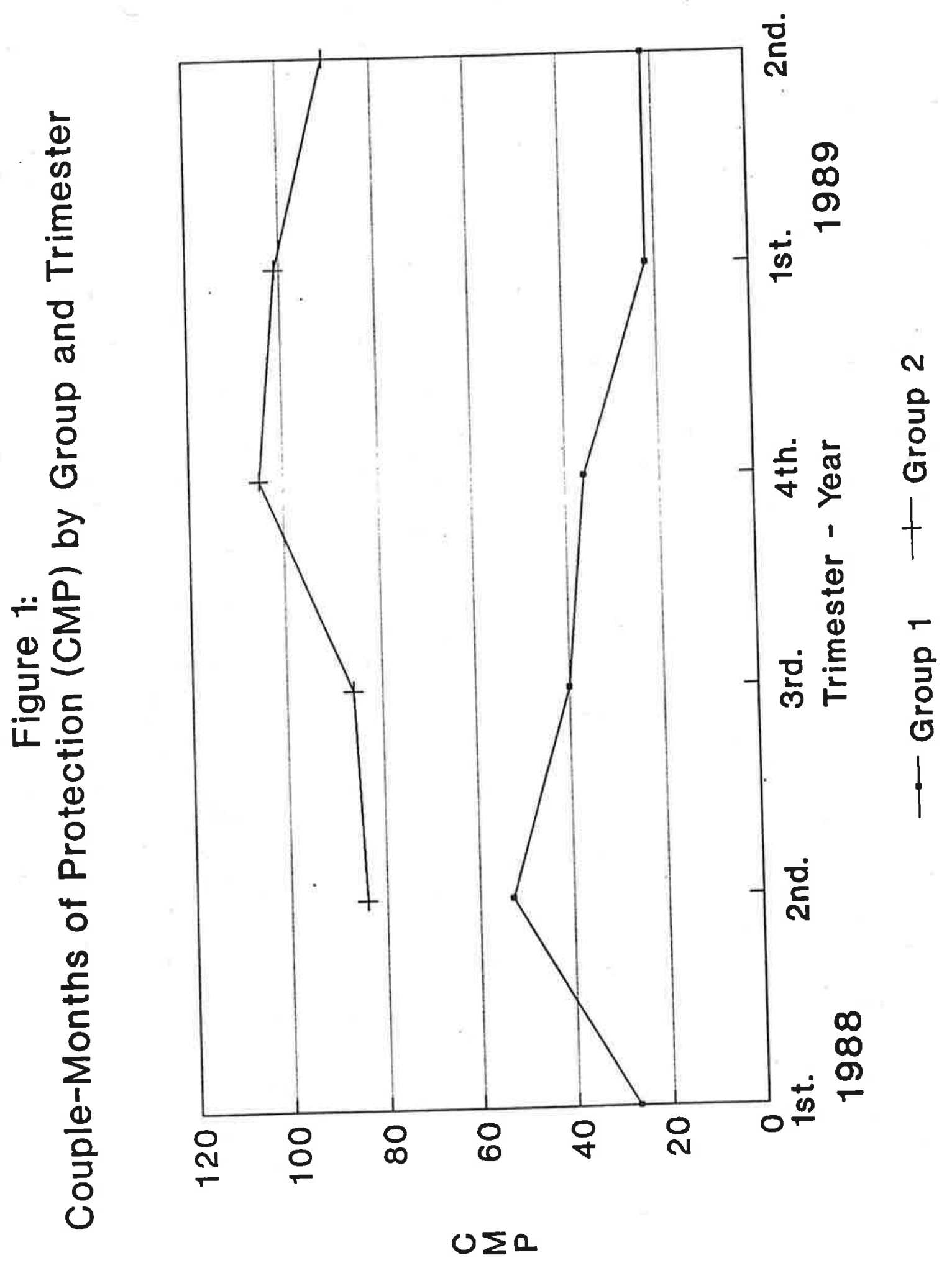


For additional information on the INOPAL Program, please contact The Population Council Regional Office in Mexico (Apartado Postal 105-152, 11560 Mexico, D. F.I, The Population Council in New York IOne Dag Hammarskjold Plaza, New York, NY 10017), or Office of Population, ST/POP, Agency for International Development, Washington, D. C. 20523.

The agencies with which INOPAL collaborated were:

\section{BARBADOS}

Barbados Family Planning Association (BFPA). Bay Street, St. Michael, Barbados, W.I. Strategies to increase the use of contraceptives by factory workers in Barbados, and a study of the determinants of condom use in two Eastern Caribbean Countries: Barbados and St. Lucia.

\section{BOLIVIA}

Centro de Investigación, Educación y Servicios (CIES). Edif. Santa Isabel, Bloque C2203, La Paz, Bolivia, S.A. A CBD program with a medical back-up component for union groups in La Paz.

\section{BRAZIL}

Assistencia Medica a Industria e Comercio Ltda. (AMICO). Rua Azevedo Macedo 92, CEP 04013, Sao Paulo SP, Brazil, S.A. Assessing costs and benefits of incorporating family planning into a pre-paid HMO plan in Brazil.

Associacao Brasileira de Entidades de Planejamento Familiar (ABEPF). Rua Visconde Silva 25, Botafogo-22271, Rlo de Janeiro, Brazil, S.A. Alternatives to expand family planning services in Brazil.

Promocao da Paternidade Responsavel (PRO-PATER). Rua Marques de Paranagua 359, 01303 Sao Paulo, Brazil, S.A. Measuring the cost-effectiveness of mass media promotion of vasectomy.

\section{COLOMBIA}

Asociación Sociedad Médico Farmacéutica (SOMEFA). Carrera 6a. No. 76-34, Bogotá, D.E., Colombia, S.A. A cost-effective strategy to distribute IUDs among private physicians in Colombia.

Asociación Pro-Bienestar de la Familia Colombiana (PROFAMILIA). Calle 34 No. 1452, Bogota, Colombia, S.A. IEC services and condom distribution for AIDS and STD prevention. 
Asociación Pro-Bienestar de la Familia Colombiana (PROFAMILIA). Calle 34 No. 1452, Bogotá, Colombia, S.A. Operations research on different approaches for vasectomy service provision in Colombia.

\section{DOMINICAN REPUBLIC}

Asociación Dominicana Pro Bienestar de la Familia (PROFAMILIA). Socorro Sánchez 64, Zona 1, Santo Domingo, República Dominicana, C.A. Strengthening human resources program expansion.

Asociación Dominicana Pro Bienestar de la Familla (PROFAMILIA). Socorro Sánchez 64, Zona 1, Santo Domingo, República Dominicana, S.A. Testing counseling options for provider-dependent contraceptive methods.

\section{ECUADOR}

Centro Médico de Orientación y Planificación Familiar (CEMOPLAF). Flores 912 y Manabi, Quito, Ecuador, C.A. Delivery of family planning and health services in rural communities in Ecuador.

\section{GRENADA}

Grenada Planned Parenthood Association (GPPA). P. O. Box 127, St. George's, Grenada, W.I. Strategies to promote contraceptive use among women with high reproductive risk.

\section{GUATEMALA}

Asociación Pro-Bienestar de la Familia de Guatemala (APROFAM). 9a. Calle 0-57, Zona 1, Guatemala, Guatemala, C.A. Improving the performance of distributors in APROFAM's CBD program in indigenous areas.

Asociación Guatemalteca de Educación Sexual (AGES). 3a. Calle 3-59, Zona 1, Guatemala, Guatemala, C.A. Client-designed family planning service delivery systems.

\section{HONDURAS}

Federación de Organizaciones Privadas (FOPRIDEH/PROALMA). Tercer Piso Edif. Junta Nacional de Blenestar Soclal, Teguclgalpa, Honduras, C.A. Promotion of breastfeeding and family planning in the Soclal Security Institute of Honduras.

Asociación Hondureña de Planificación Familiar (ASHONPLAFA). Bo. San Felipe, Calle Pueblo Nuévo, Casa No. 3368, Tegucigalpa, F.M., Honduras, C.A. Strategy to increase the availability and use of the copper IUD through private physicians. 
Instituto Hondureño de Seguridad Social (IHSS). Segunda Avenida y 8a. Calle, Tegucigalpa, D.C., Honduras, C.A. Providing family planning services on the basis of reproductive risk: Honduras.

\section{JAMAICA}

The Women's Centre (TWC). 42 Trafalgar Rd., Kingston 6, Jamaica, W.I. An evaluation of the effect of continuing education on teenage childbearing.

\section{MEXICO}

Pro-Superación Familiar Neolonesa, A.C. (PSFN). Blvd. Dlaz Ordaz 120, Col. Santa Marla, Monterrey, N.L., México. Integral development of young adults in the community: Nuevo León.

Materno Infantil y de Planificación Familiar, A.C. (MIPFAC). Plutarco Ellas Calles 744 Norte, 32310 "Ciudad Juárez, Chih., México. Family planning service delivery strategies in an industrial setting.

Fundación Mexicana para la Planeación Familiar, A.C. (MEXFAM). Juárez 208, Tlalpan, 14000 México, D.F., México. The use of operations research as a management tool: MEXFAM.

Academia Mexicana de Investigación en Demografla Médica (IMSS/AMIDEM). Mier y Pesado 120, Col. del Valle, 03100 México, D.F., México. The impact of providing family planning services on the basis of reproductive risk in Mexico.

Promotora de Planificación Familiar, A.C. (PROFAM). Circuito Balvanera No. 3, Fracc. Industrial Balvanera, 76900 Villa Corregidora, Qro., México. The marketing of condoms in supermarkets: Shelf vs. cashier as point of sale.

Centro de Orientación para Adolescentes, A.C. (CORA). Tenayuca No. 55 - Desp. 701/702, Col. Vértiz Narvarte, México, D.F., México. Cost-effectiveness study on the services to young adults in Mexico.

Federación Mexicana de Asociaciones de Planificación Familiar, A.C. (FEMAP). Plutarco Ellas Calles 744 Norte, 32310 Cludad Juárez, Chih., México. Testing strategies to increase men's involvement In family planning.

Centro de Investigación sobre Fertilidad y Esterilidad, A.C. (CIFE). Bajfo 203 - Desp. 101, Col. Roma Sur, 06760, México, D.F., México. The effectiveness of the private physician in the implementation of a male-only clinic. 
Mercadotecnia Social Aplicada, A.C. (MSA). Circuito Balvanera No. 3, Fracc. Industrial Balvanera, 76900 Villa Corregidora, Qro., México. The effectiveness of social marketing strategies in the implementation of a male-only clinic.

Dirección General de Epidemiologla (CONASIDA). Aniceto Ortega No. 1321 - 50. Piso, Col. del Valle, 03100 México, D.F., México. The impact of Mexico's mass media campaign on AIDS prevention.

Fundación Mexicana para la Planeación Familiar, A.C. (MEXFAM). Juárez 208, Tlalpan, 14000 México, D.F., México. Incorporating educational strategies into family planning programs for the prevention of AIDS.

Instituto Mexicano de Investigación de Familia y Población, A.C. (IMIFAP). Pennsylvania No. 173 - Depto. 2, Col. Nápoles, México, D.F., México. Family life education program for young adults.

\section{PARAGUAY}

Centro Paraguayo de Estudios de Población (CEPEP). Manduvira y Juan E. O'Leary, 8o. Piso, Edificio El Dorado, Asunción, Paraguay, S.A. Test of a strategy to expand family planning service delivery in Gran Asunción, Paraguay.

Centro Paraguayo de Estudios de Población (CEPEP). Manduvira y Juan E. O'Leary, 8o. Piso, Edificio El Dorado, Asunción, Paraguay, S.A. A rural family planning service delivery model in Paraguay.

\section{PERU}

Instituto Peruano de Paternidad Responsable (INPPARES). Gregorio Escobedo 115 , Jesús Marla, Lima 11, Perú, S.A. An experiment to improve IUD insertion and medical back-up of a CBD program.

Asociación para el Desarrollo e Integración de la Mujer (ADIM). Jr. Vandyck No. 281, San Borja, Lima, Perú, S.A. Integrating family planning services with women's development activities.

Vecinos Perú (VECINOS). Av. Javier Prado Este 4921, Ofna. 4, La Molina, Lima 12, Perú, S.A. Operations research to improve Ministry of Health family planning services in Peru.

INPPARES/PRO-FAMILIA/APROSAMI (SPF). Gregorio Escobedo 115, Jesús Marla, Lima 11, Perú, S.A. Evaluating the impact of regionalization on three family planning agencies in Lima. 
Instituto Peruano de Paternidad Responsable (INPPARES). Gregorio Escobedo 115, Jesús María, Lima 11, Perú, S.A. An experiment to improve quality of care in a Peruvian CBD program.

Instituto Peruano de Seguridad Social/PROFAMILIA (IPSS). Jr. Trípoli 360, Miraflores, Lima 18, Perú, S.A. Immediate post-partum and post-abortion family planning program.

PROFAMILIA/CENPROF. Bolognesi 465, Trujillo, Perú, S.A. A comparison of male and female community based distributors of contraceptives.

Universidad Nacional Mayor de San Marcos. Horacio Urteaga 1571, Lima 11, Perú, S.A. Family planning programs for special groups of high risk women.

Universidad Peruana Cayetano Heredia. Av. Honorio Delgado No. 430, Urb. Ingenierla, Sam Martin de Porras, Aptdo. 5045, Lima, Perú. Collaborative pre-introduction study of the clinical performance and acceptability of Norplant ${ }^{\mathrm{a}}$ in Peru.

Ministerio de Salud/Proyectos en Informática, Salud, Medicina y Agricultura (MOH/PRISMA). Av. Las Artes 360, San Borja, Lima 41, Perú, S.A. Involving family planning workers in an AIDS prevention campaign in Lima.

\section{ST.KITTS-NEVIS}

Ministry of Health, Education \& Community Affairs (MOHECA). Basseterre, St. KittsNevis, W.I. Increasing male use of contraceptives. 


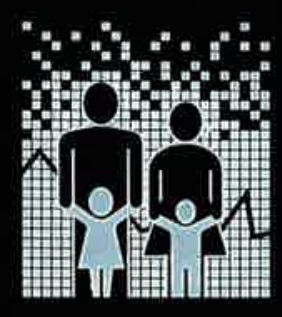

